\title{
Numerical Analysis of Cyclic Loading effect on Progressive Failure in Earth Damsupona Multiline-Multilaminate Model
}

\author{
Hamzeh Rahimi Dadgar ${ }^{1}$, M.A.Arjomand ${ }^{2 *}$, Ali Arefnia ${ }^{3}$ \\ ${ }^{1,3}$ Department of Civil Engineering, Roudehen Branch, Islamic Azad University, Roudehen, Iran. \\ E-mail: st.h_rdadgar@riau.ac.ir,a.arefnia@riau.ac.ir \\ ${ }^{2}$ Assistant Professor, Faculty of Civil Eng., ShahidRajaee Teacher Training University, Tehran, Iran. \\ E-mail: arjomand@sru.ac.ir(Corresponding Author)
}

\begin{abstract}
Dam construction is one of the major development planning policies. The observation of the criteria and standards codified in every country for the achievement of a safe plan is also a major principle. A progressive failure is highly likely if fracture occurs in each section of an earth dam due to dynamic loads. Since such an inspection needs precise modeling and defining of the proper boundary conditions in high accuracy, multiline models have been taken into account herein through taking advantage of multiline pattern. Pattern parameters have been applied in the present study for confining pressures by comparing behavioral pattern with the results of standard triaxial experiment for three different confining pressure rates. Next, for dynamic (cyclic) state, the results obtained from the behavioral pattern will be compared with the results of the standard triaxial laboratory results. To observe the accuracy of the behavioral pattern's performance for cyclic loading mode, use was made of the results of a cyclic triaxial experiment conducted by Anlong Lia et al. for confining 2MPa, 10MPa, 20MPa, 30MPa, 40MPa and 50MPa pressures. After adding the new model to OpenSees numerical analysis, it is necessary to reensure the accuracy of the multilinear behavioral model's performance within the format of the multilaminate theory. Thus, to do so, a standard cyclic triaxial experiment was conducted with the same dimensions and the same boundary conditions and with strain in a confining pressure of 10KPa for the dynamic loading state following which the stress-strain and volumetric strainaxial strain curves were drawn for them and the behaviors were obtained for the new model in the finite element space and the laboratory results were eventually compared.
\end{abstract}

Keywords: Earth dam, Progressive Failure, Multiline-Multilaminate Model, Dynamic Analysis, Confining Pressure

\section{Introduction:}

For their great many of the advantages in contrast to the other dams such as low construction costs, fast and easy implementation, capability of being constructed on various kinds of foundations, etc., earth-gravel dams have always been the focal point of attention and a wide variety of research has been carried out on these dams in various fields [1].

On the other hand, Many Countries are located in an earthquake-prone region and the investigation of the behavior of the earth dams against dynamic loads and the examination of the various probable methods of these dams' destruction is of great importance. If fracture is developed in each of the earth dam sections due to dynamic loading, progressive failure would be very much likely to occur. This phenomenon occurs during earthquake as well as after earthquake as a result of the redistribution of pore pressure. One method of evaluating the stability and performance of earth dams during earthquake is the use of dynamic analysis that is performed via numerical analysis methods such as finite element and finite difference methods and it, possibly, provides access to sufficient information about the dynamic behavior of soil hence more realistic results of the dam's seismic response [2].

Some studies have also been conducted in this regard. In the analysis of each structure parallel to the determination of the stresses and deformations, the correct behavior of its constituent constructional materials against the imposed loads should be seminally recognized. Then, it is by the selection of the proper behavioral pattern that it can be analyzed. Some phenomena, including viscosity cause changes in the nonlinear behavior of the geomaterials and this renders difficult the analysis of the earth structures [3]. In 2004, Glagovsky and Casirova performed a numerical analysis on a concreteface rockfilldams [4] and this research became a premise for Bayractar et al. to carry out a numerical modeling in 2012 based on finite element in a state of nonlinear loading of concretefacerockfill dams [5]. Bulatov et al. figured out the specific importance of crack inspections in the analysis of the earth dam's behavior in an investigation of the prior numerical research and the results obtained from instrumentation and dealt with numerical examination of cracking effect on the behavior of the earth dam with clay core [6]. 
The multilaminate method used in the current research paper was performed by such researchers as Zienkiewicz and Pande in 1977 and Pande and Sharma in 1983 [7] and Sadrnejad and Pande [8]. It is worth mentioning that Sadrnejad et al. [8\&9] performed a lot of studies for the simulation of the behavior of inhomogeneous sand and rocks as well as regarding the viscosity potentials [10\&11]. The present research paper tries creating a process based on a multilinear method within the format of a multiplane model that can be applied for various conditions, including the existence of pore-water pressure, and for various geomaterials with different stressstrain history for numerical and dynamic analyses.

\section{Study Method:}

Multilinepatterns can be simulated for approximating the real nonlinear behavior for all of the constructional materials, especially for soil and rock masses, in the form of considering numerous linear behaviors on stress and strain occurrence path. In other words, the existent nonlinear behavior can be divided into a number of limited lines with linear tensile behavior. Incremental Hook's law or grade zero hypoelastic law is predominantly taken into consideration as the behavioral axiom for the simulation of these behavioral patterns. The general deformation of such materials can be classified as either reversible or irreversible.

In quasi-linear and multiline patterns, the continuity equation for incremental pattern takes the following form:

$$
\begin{aligned}
& d \varepsilon_{k l}^{m}=C_{i j k l}^{t m} d \sigma_{i j}^{m} \text { Equation (1) } \\
& \left\{d \varepsilon_{m}\right\}=\left[C_{t m}\right]\left\{d \sigma_{m}\right\}_{\text {Equation (2) }}
\end{aligned}
$$

Or,

$$
\begin{aligned}
& d \sigma_{i j}^{m}=D_{i k l}^{t m} d \varepsilon_{k l}^{m} \text { Equation (3) } \\
& \left\{d \sigma_{m}\right\}=\left[D_{t n}\right]\left\{d \varepsilon_{m}\right\} \text { Equation (4) }
\end{aligned}
$$

Where, $\mathrm{m}$ denotes the $\mathrm{m}^{\text {th }}$ increment of the stress, $d \sigma$, and the strain, $d \varepsilon$, and designates the continuity (slope) matrix corresponding to the $\mathrm{m}^{\text {th }}$ increment. Matrix $\left[C_{t m}\right]$ takes different shapes in various increments and it is often calculated in the form of a slope in one point of the $\mathrm{m}^{\text {th }}$ increment [12].

In soil mechanics problems, deviatoric stress, axial strain and volumetric strain-axial strain curves are often utilized simultaneously.

Stress vector on each plane of the 17 planes is as shown below:

$$
\sigma_{j}=\left\{\begin{array}{c}
\sigma_{n} \\
\tau_{1} \\
\tau_{2}
\end{array}\right\}
$$

\section{Equation (5)}

To investigate the collapse criteria, the relationship between the vertical stress and shear stress should be determined on each plane. According to the fact that the amounts of the shear stress are expressed by two indicators on the suggested model's planes, the output of the shear stress on the plane is used as demonstrated below:

$$
\tau=\sqrt{\tau_{1}^{2}+\tau_{2}^{2}} \text { Equation (6) }
$$

Therefore, it is by the delineation of the stress path for each plane in the normal stress-shear stress space and comparing it with Mohr-Coulomb line that the plane in the direction of which materials reach collapse point earlier can be determined. 


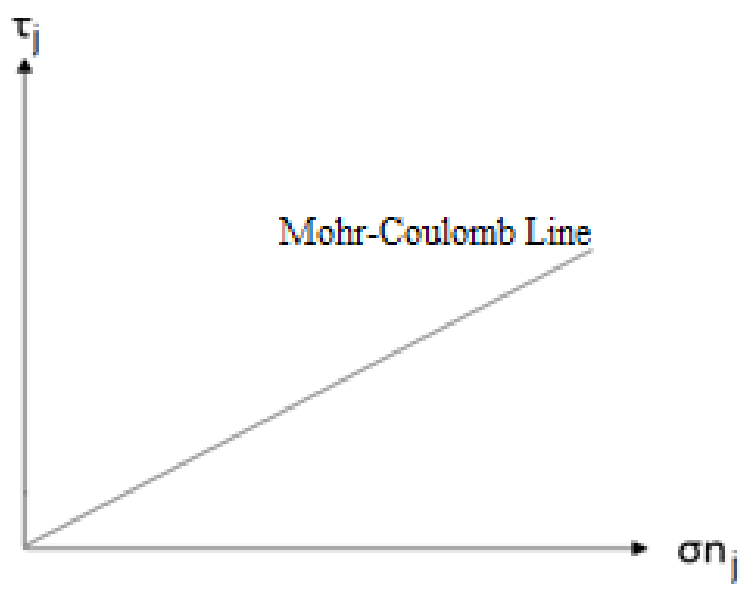

Figure (1): Mohr-Coulomb line in the shear stress-normal stress space on $\mathrm{j}^{\text {th }}$ plane

In order to be able to use multilinear pattern within the format of multiplane theory in practical problems, its parameters should be firstly determined so that they can be applied to various problems in a general state. To do so, the behavioral model should be matched to experimental data. In the present study, the behavioral pattern was compared with the results of the standard triaxial experiment for three confining pressures so that the pattern parameters can be applied to the confining pressures. The following section compares the results of the behavioral pattern with the standard triaxial laboratory results for the dynamic (cyclic) mode.

\section{Validation of the Behavioral Pattern's Performance for Cyclic Loading Mode:}

To observe the accuracy of the behavioral model's performance for the cyclic loading mode, use was made of the results of a cyclic triaxial experiment conducted by Anlong Lia et al, as presented in [13], for confining $2 \mathrm{MPa}, 10 \mathrm{MPa}$, 20MPa, $30 \mathrm{MPa}, 40 \mathrm{MPa}$ and $50 \mathrm{MPa}$ pressure rates. The materials' behaviors were predicted using a multilinear behavioral pattern within the format of multiplane theory and the results have been provided below. Due to the large number of the cycles, it was not possible to draw the empirical results as well as the results obtained from multilinear behavioral pattern within the format of the multiplane theory in the figure. Thus, each of them was illustrated in a separate figure.

The experiments under confining 2MPa, 10MPa, 20MPa, 30MPa, 40MPa and 50MPa pressure rates have been specified under the names $\mathrm{F}_{2}, \mathrm{~F} 10, \mathrm{~F}_{20}, \mathrm{~F}_{30}, \mathrm{~F}_{40}$ and $\mathrm{F}_{50}$, respectively.

In laboratory curves, the variation trends in the ending section of the diagram is in the form that the axial strain is increased and, as it is seen, the multilinear behavioral model has produced relatively similar results within the format of the multiplane pattern.

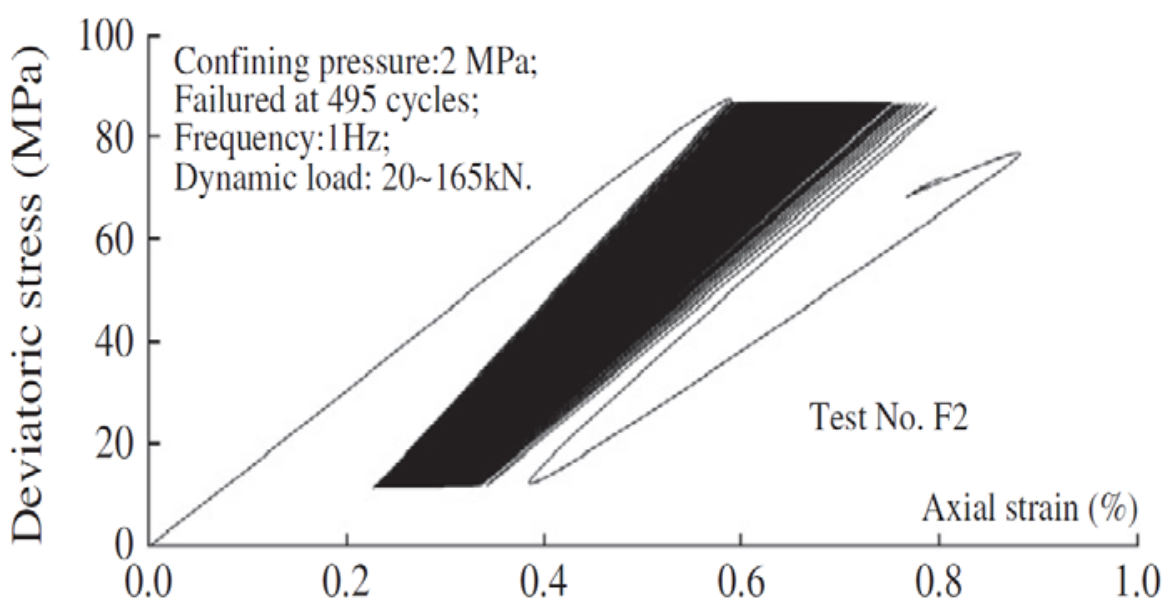

Figure (2): The laboratory results of the cyclic deviatoric stress-axial strain for confining 2MPa pressure [13] 


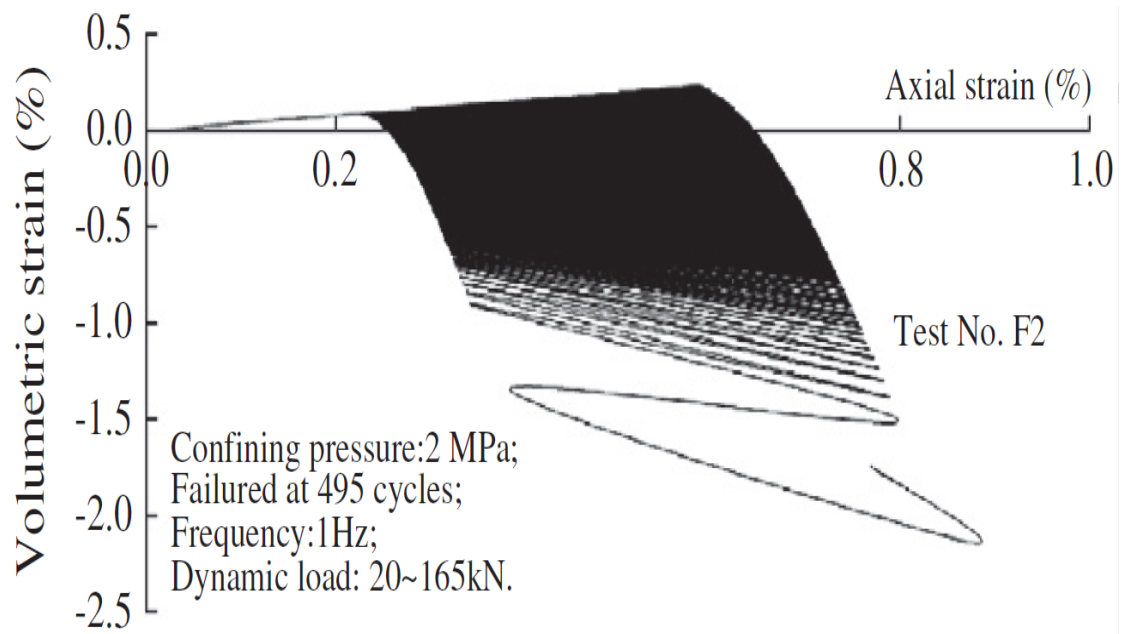

Figure (3): The laboratory results of the cyclic volumetric strain-axial strain for confining 2MPa pressure [13]

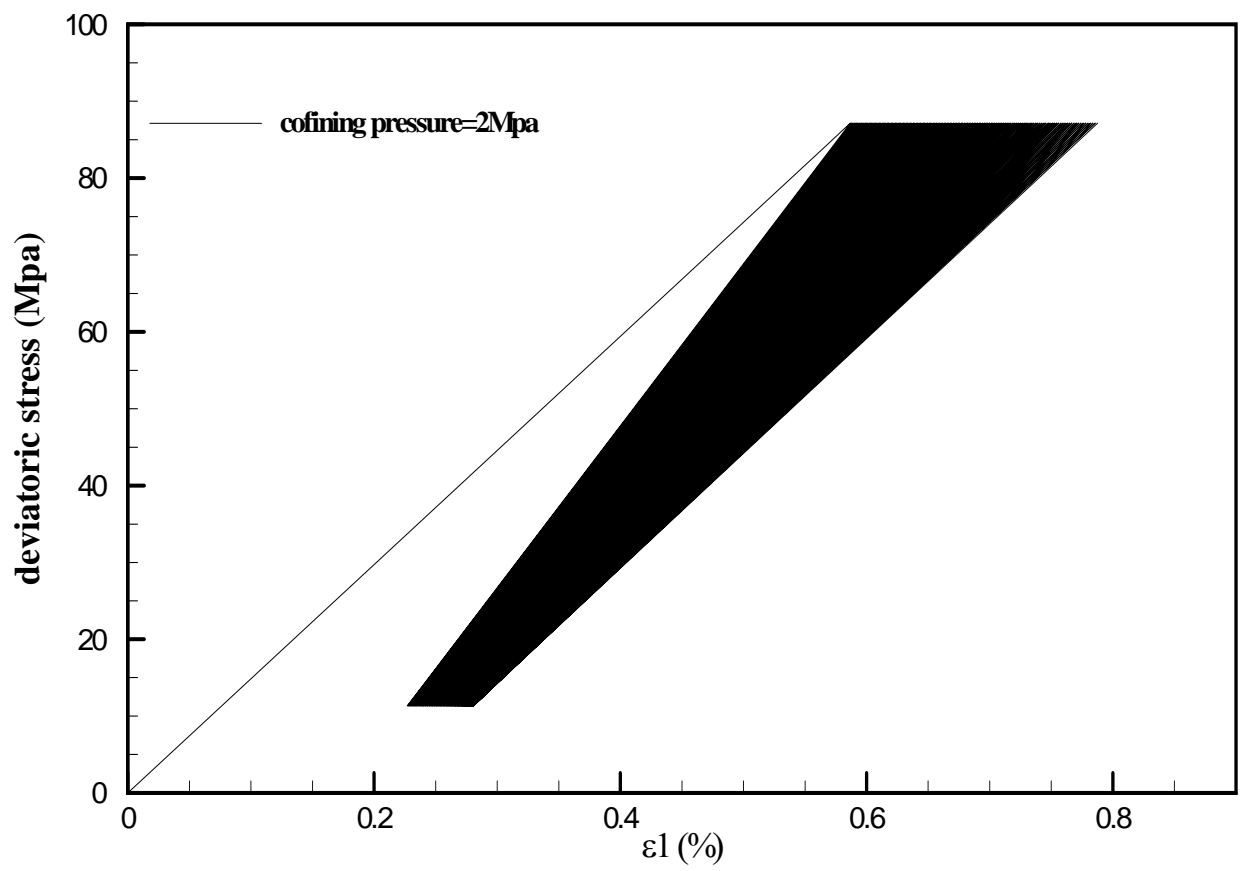

Figure (4): Cyclic deviatoric stress-axial strain for confining 2MPa pressure (Multiline-Multilaminate Model) 


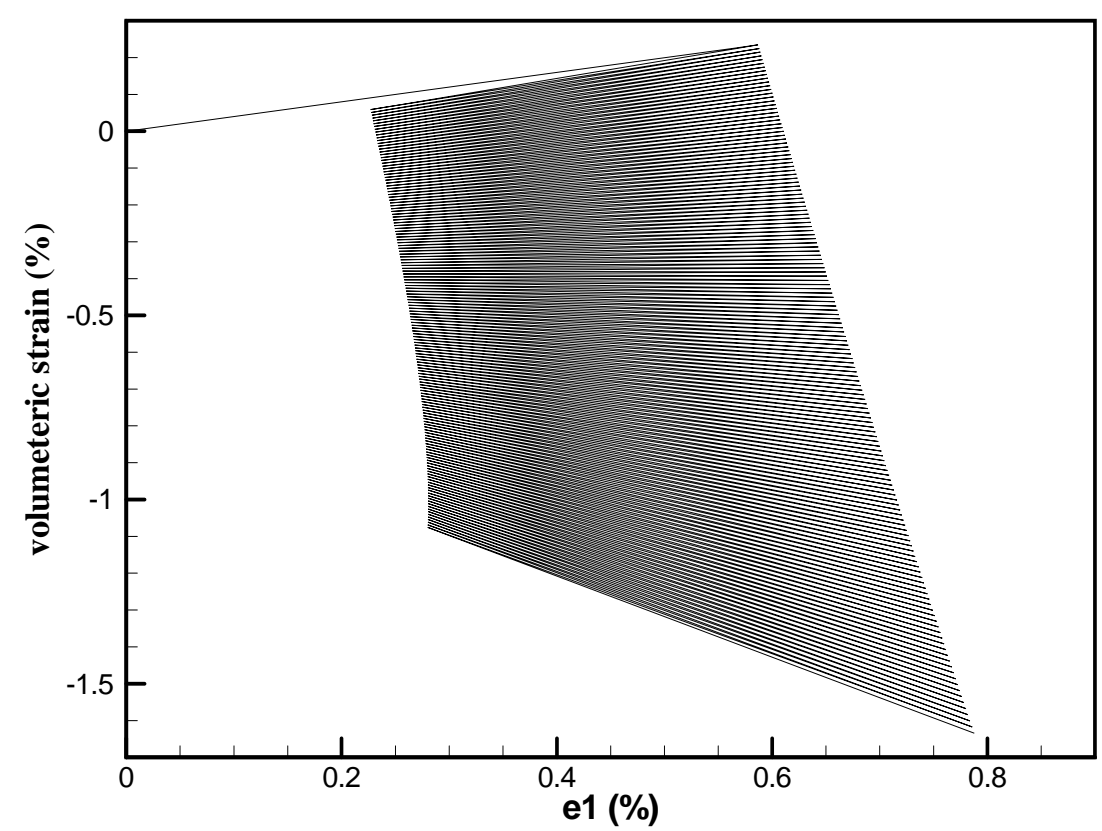

Figure (5): Cyclic volumetric strain-axial strain for confining 2MPa pressure (Multiline-Multilaminate Model)

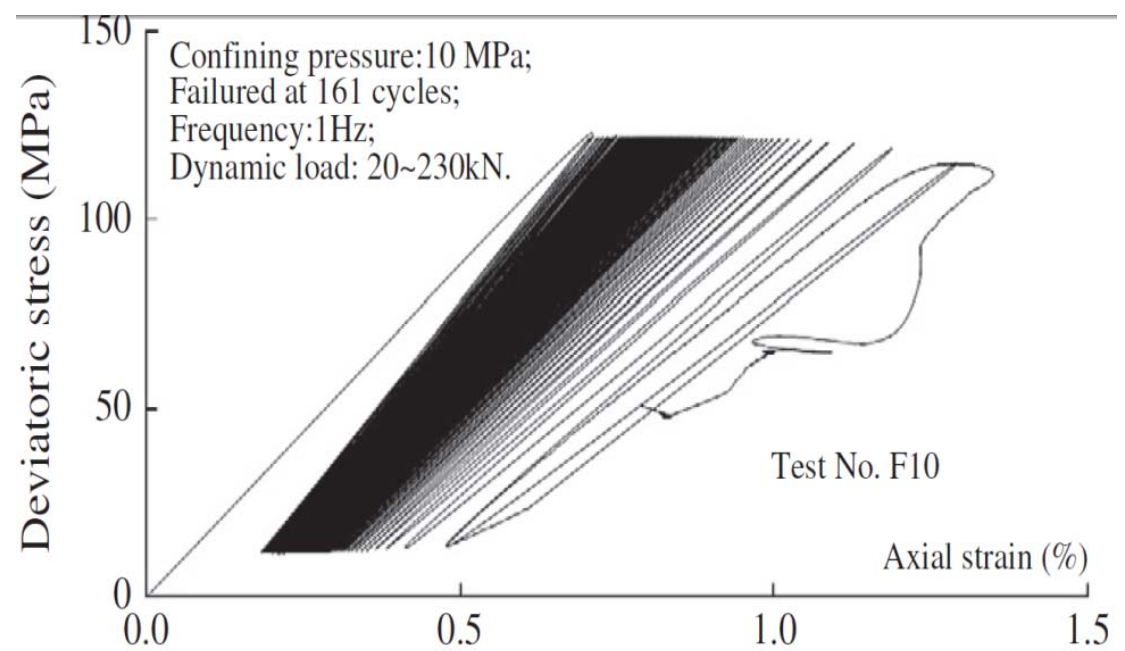

Figure (6): The laboratory results of the cyclic deviatoric stress-axial strain for confining 10MPa pressure [13]

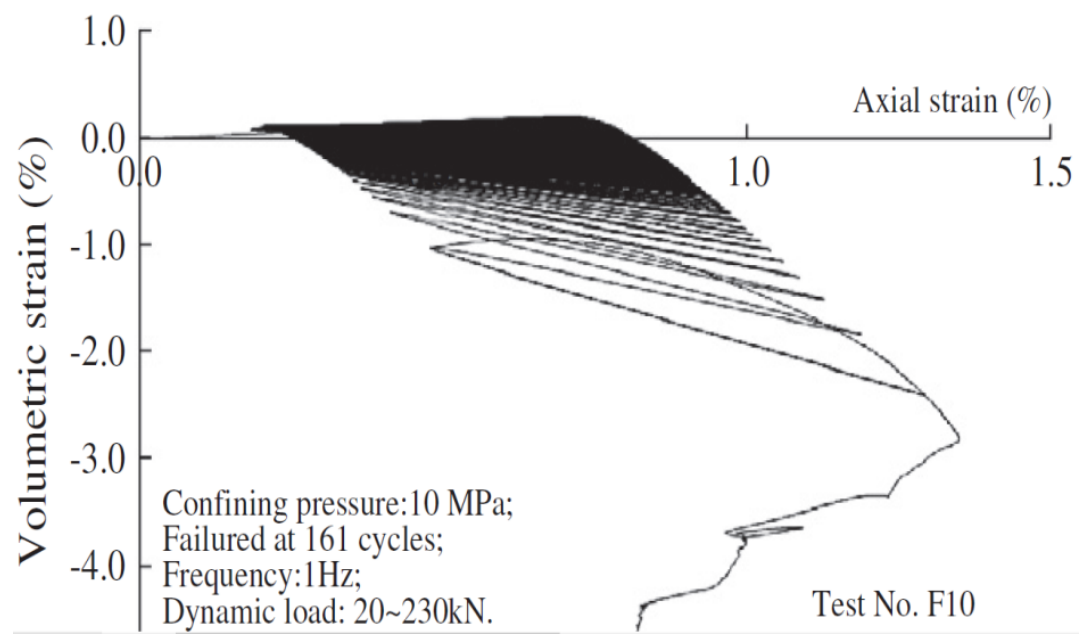

Figure (7): The laboratory results of the cyclic volumetric strain-axial strain for confining 10MPa pressure [13] 


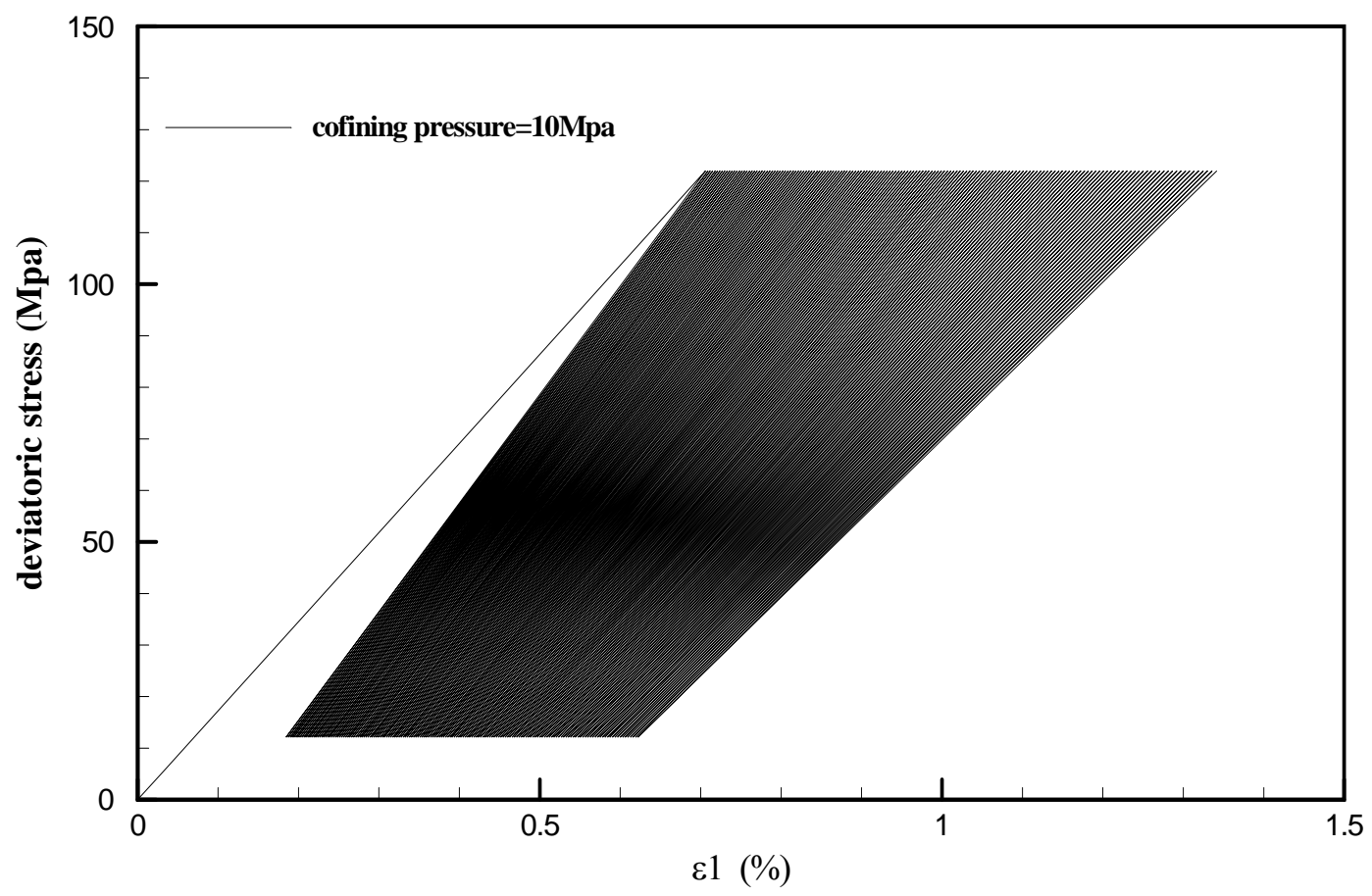

Figure (8): Cyclic deviatoric stress-axial strain for confining 10MPa pressure (Multiline-Multilaminate Model)

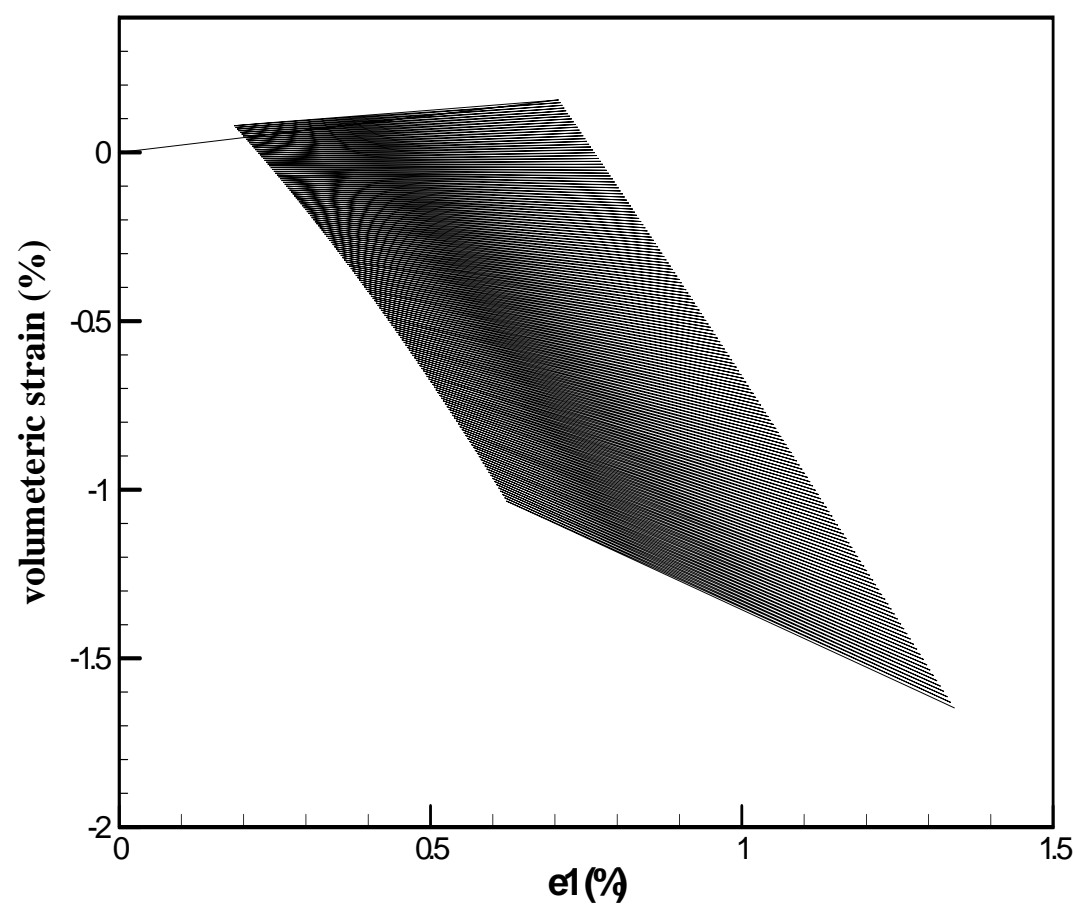

Figure (9): Cyclic volumetric strain-axial strain for confining 10MPa pressure (Multiline-Multilaminate Model) 


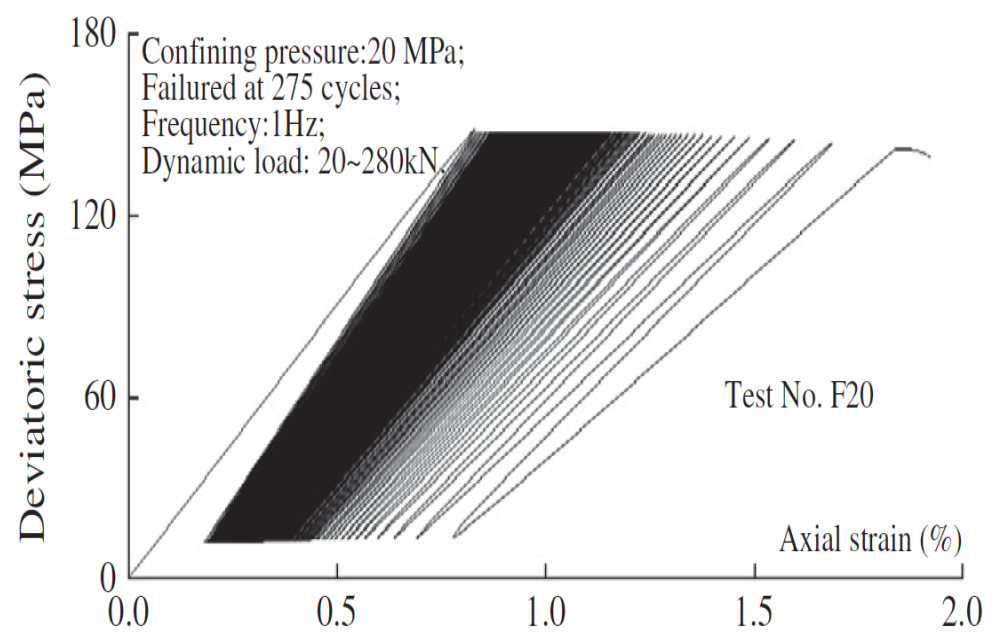

Figure (10): The laboratory results of the cyclic deviatoric stress-axial strain for confining 20MPa pressure [13]

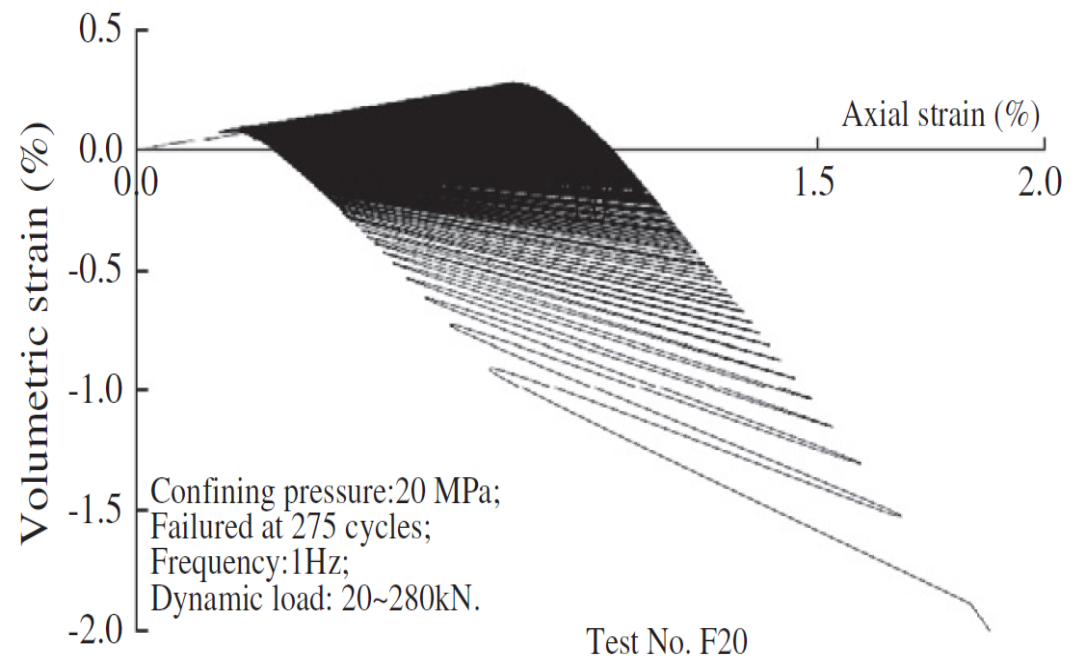

Figure (11): The laboratory results of the cyclic volumetric strain-axial strain for confining 20MPa pressure [13]

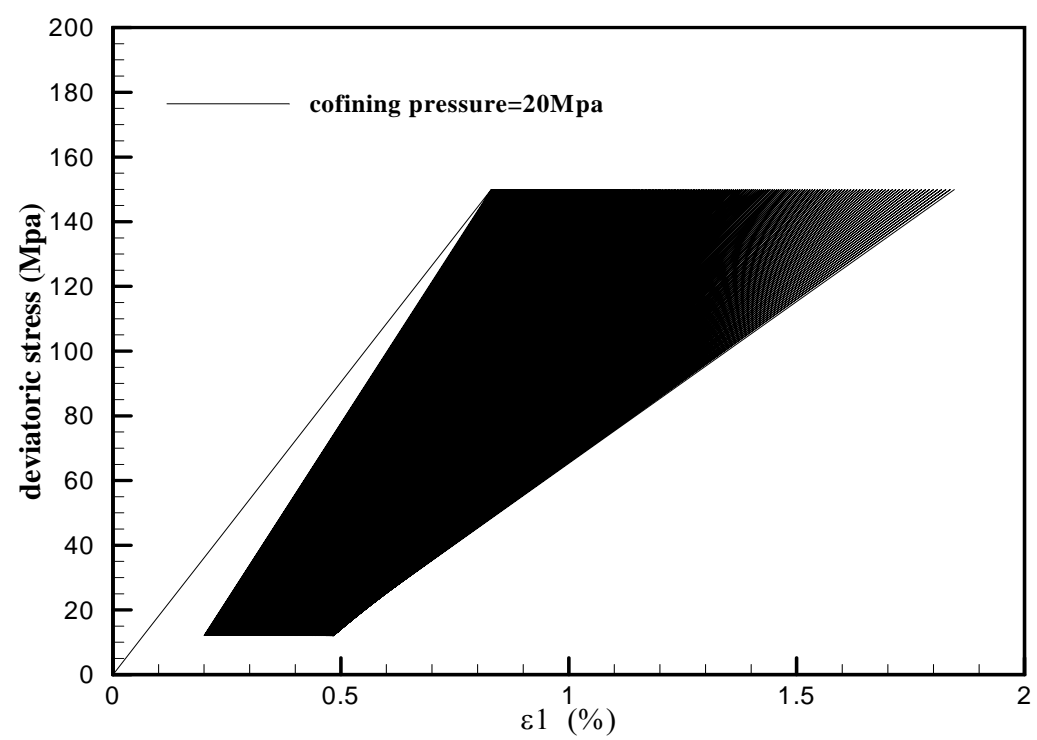

Figure (12): Cyclic deviatoric stress-axial strain for confining 20MPa pressure (Multiline-Multilaminate Model) 


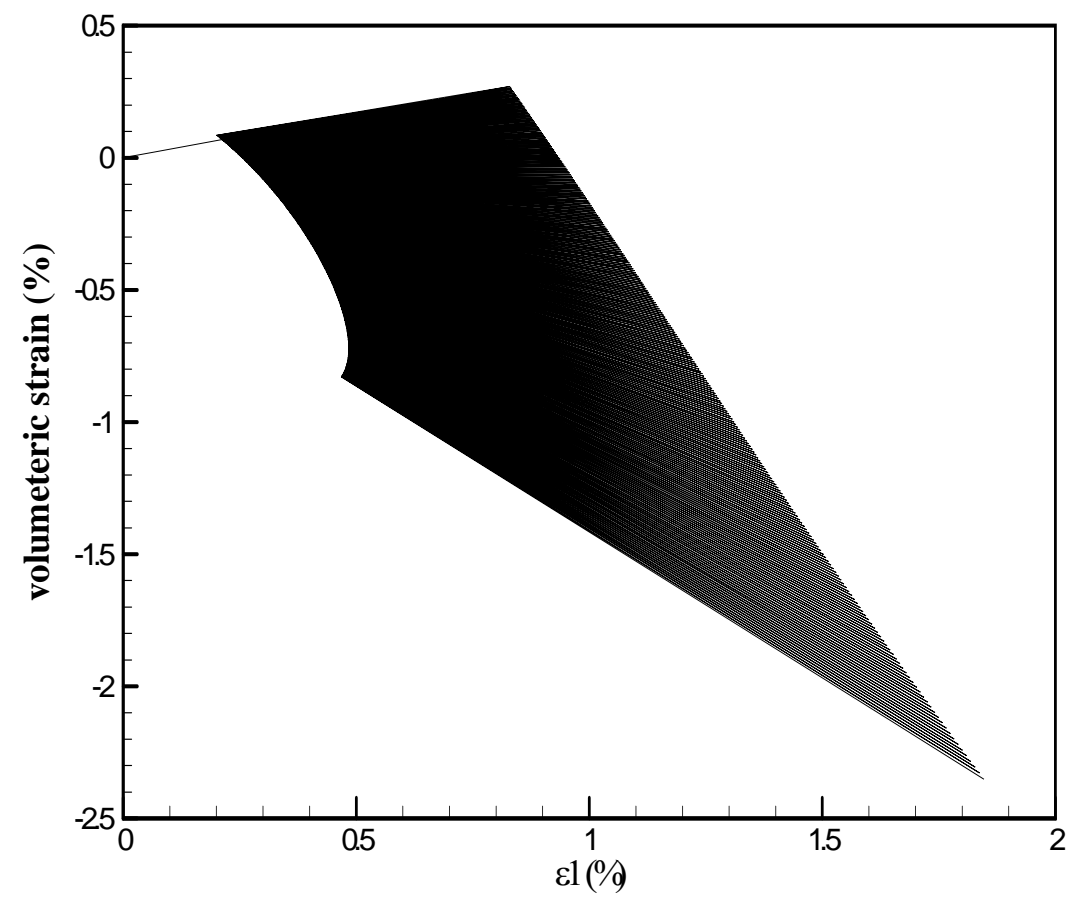

Figure (13): Cyclic volumetric strain-axial strain for confining 20MPa pressure (Multiline-Multilaminate Model)

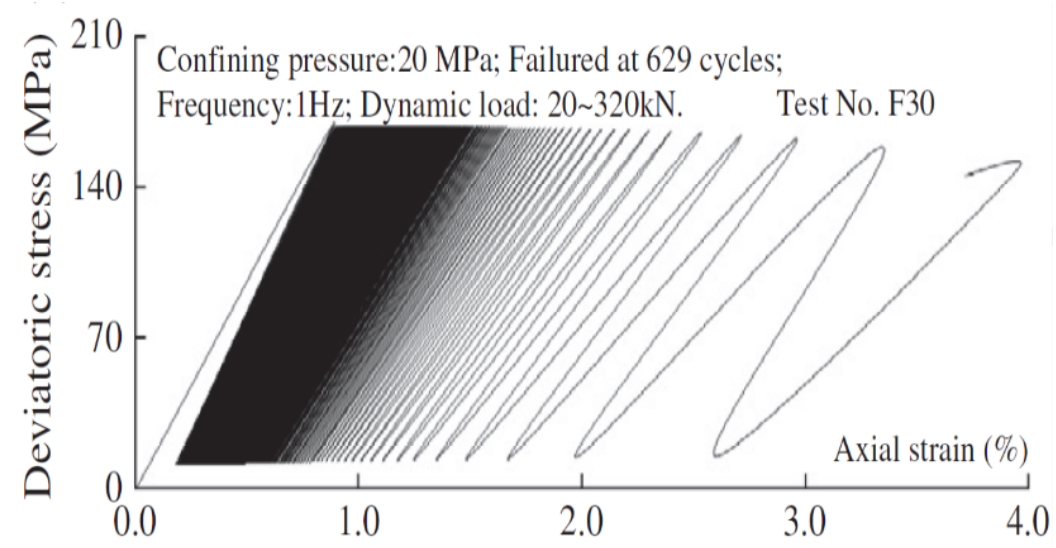

Figure (14): The laboratory results of the cyclic deviatoric stress-axial strain for confining 30MPa pressure [13]

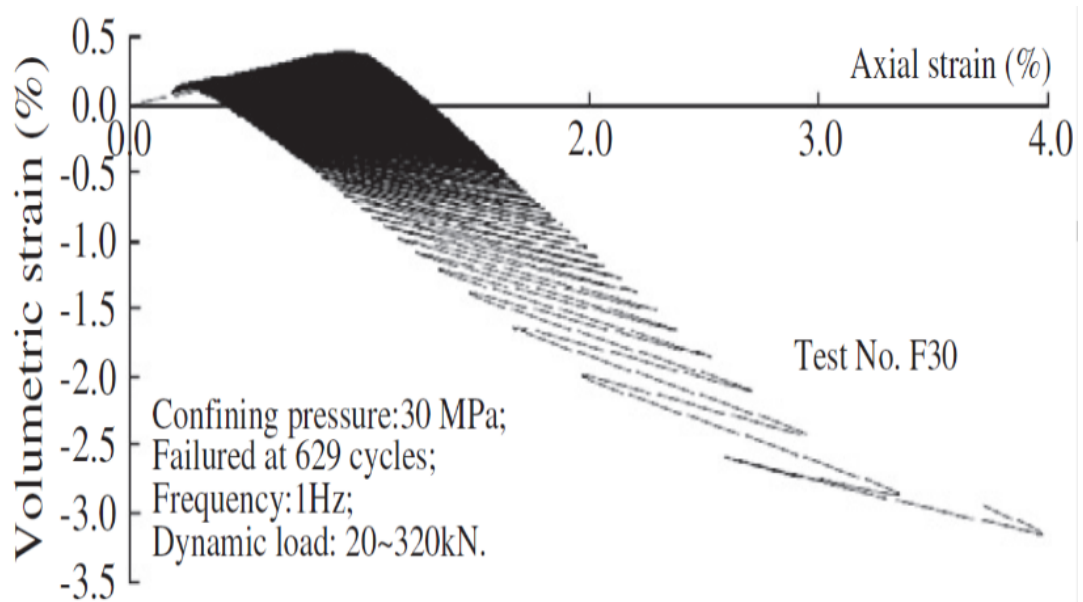

Figure (15): The laboratory results of the cyclic volumetric strain-axial strain for confining 30MPa pressure [13] 


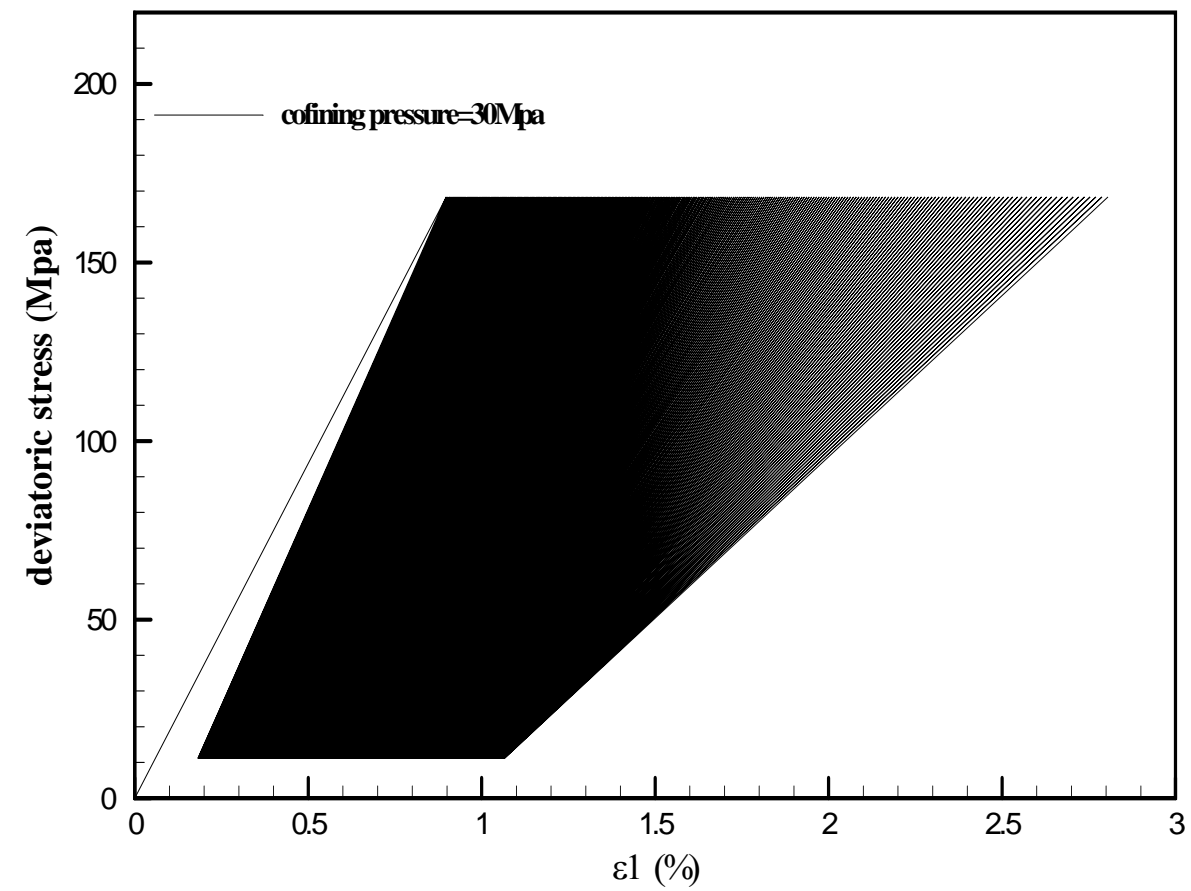

Figure (16): Cyclic deviatoric stress-axial strain for confining 30MPa pressure (Multiline-Multilaminate Model)

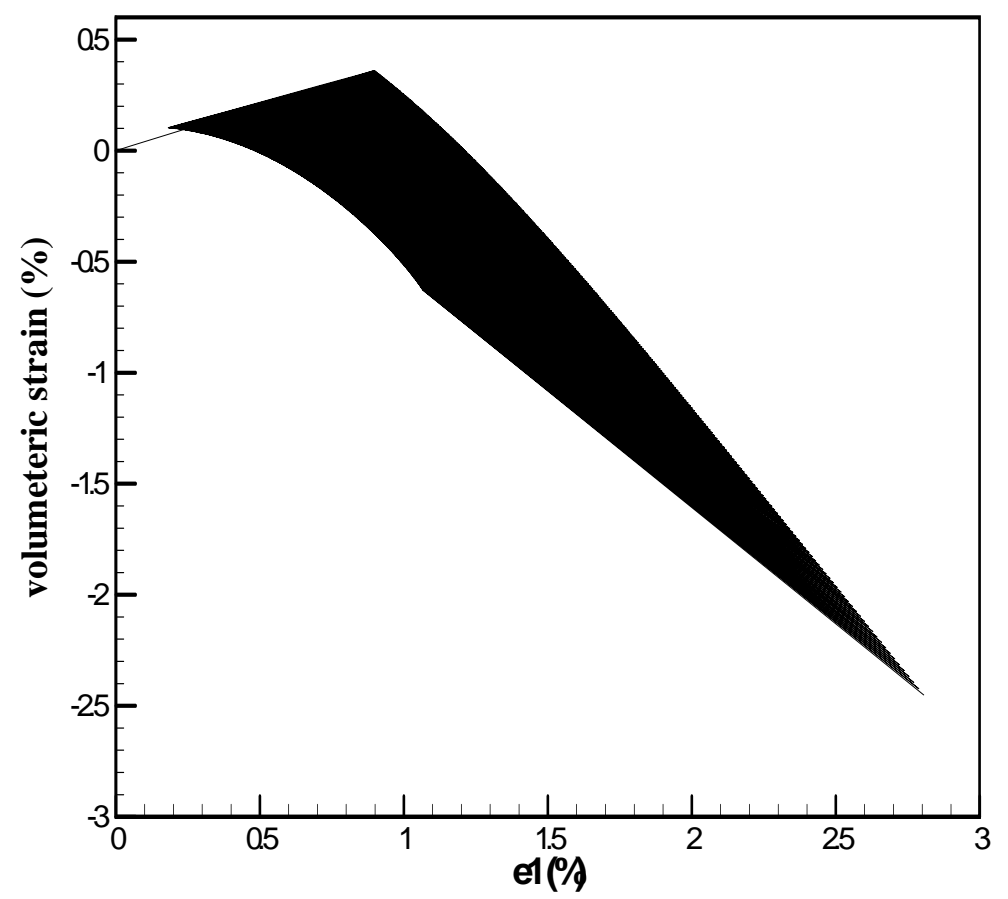

Figure (17): Cyclic volumetric strain-axial strain for confining 30MPa pressure (Multiline-Multilaminate Model) 


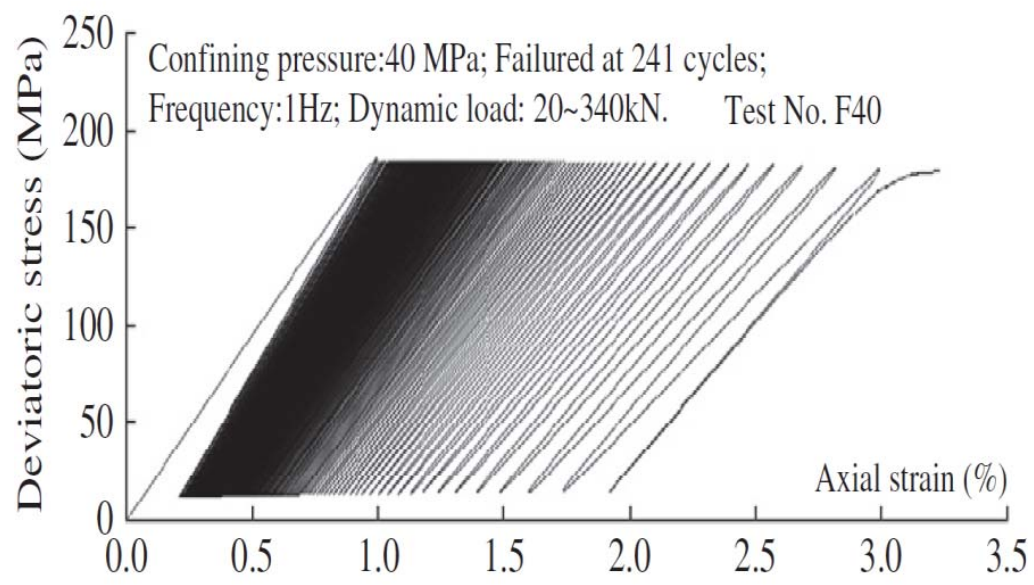

Figure (18): The laboratory results of the cyclic deviatoric stress-axial strain for confining 40MPa pressure [13]

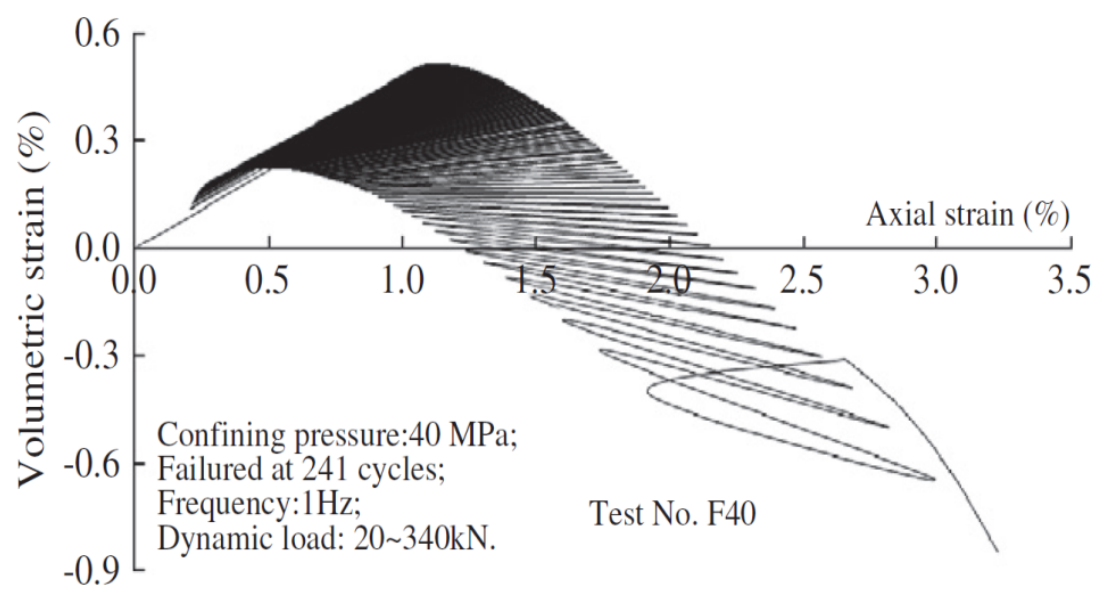

Figure (19): The laboratory results of the cyclic volumetric strain-axial strain for confining 40MPa pressure [13]

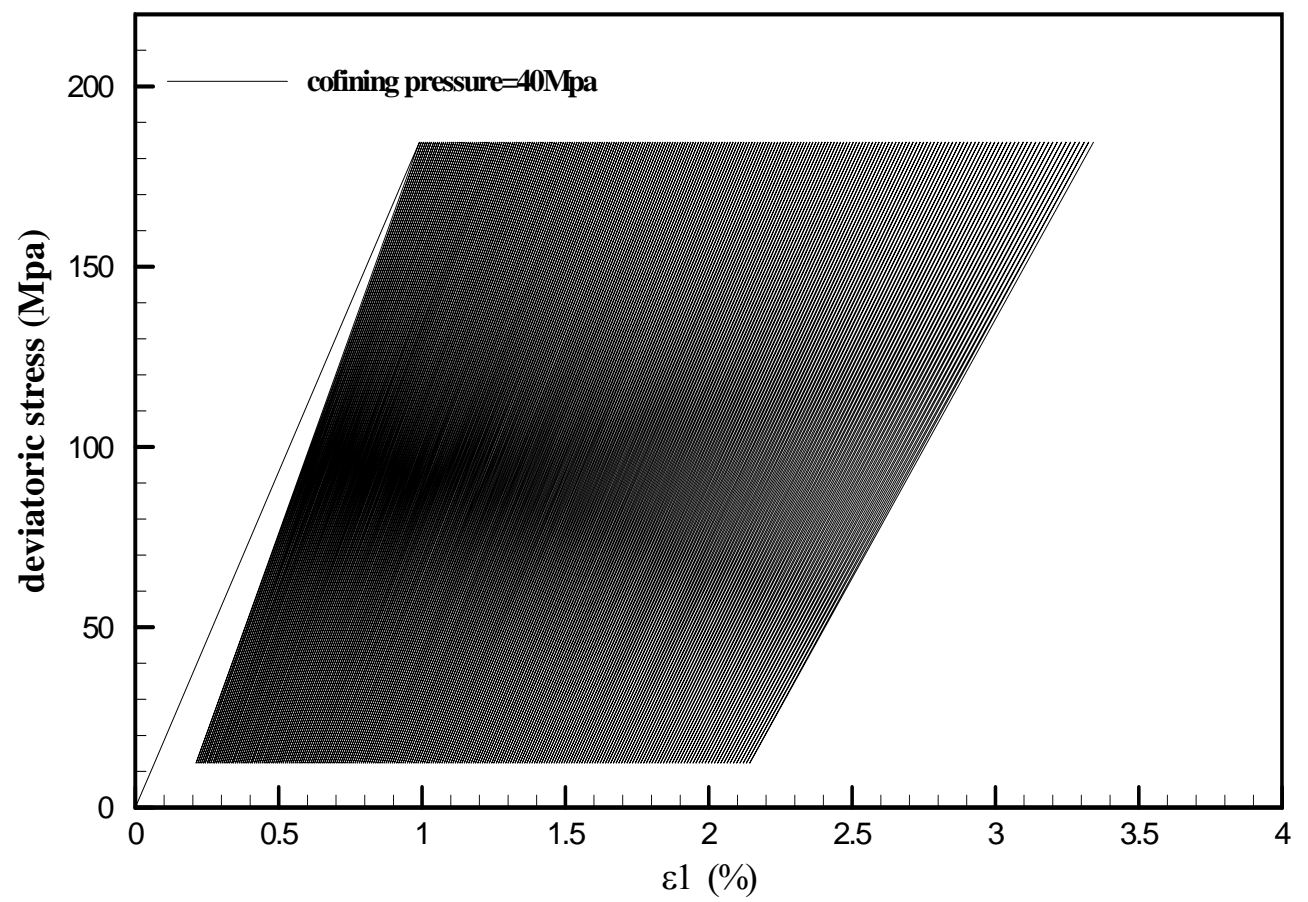

Figure (20): Cyclic deviatoric stress-axial strain for confining 40MPa pressure (Multiline-Multilaminate Model) 


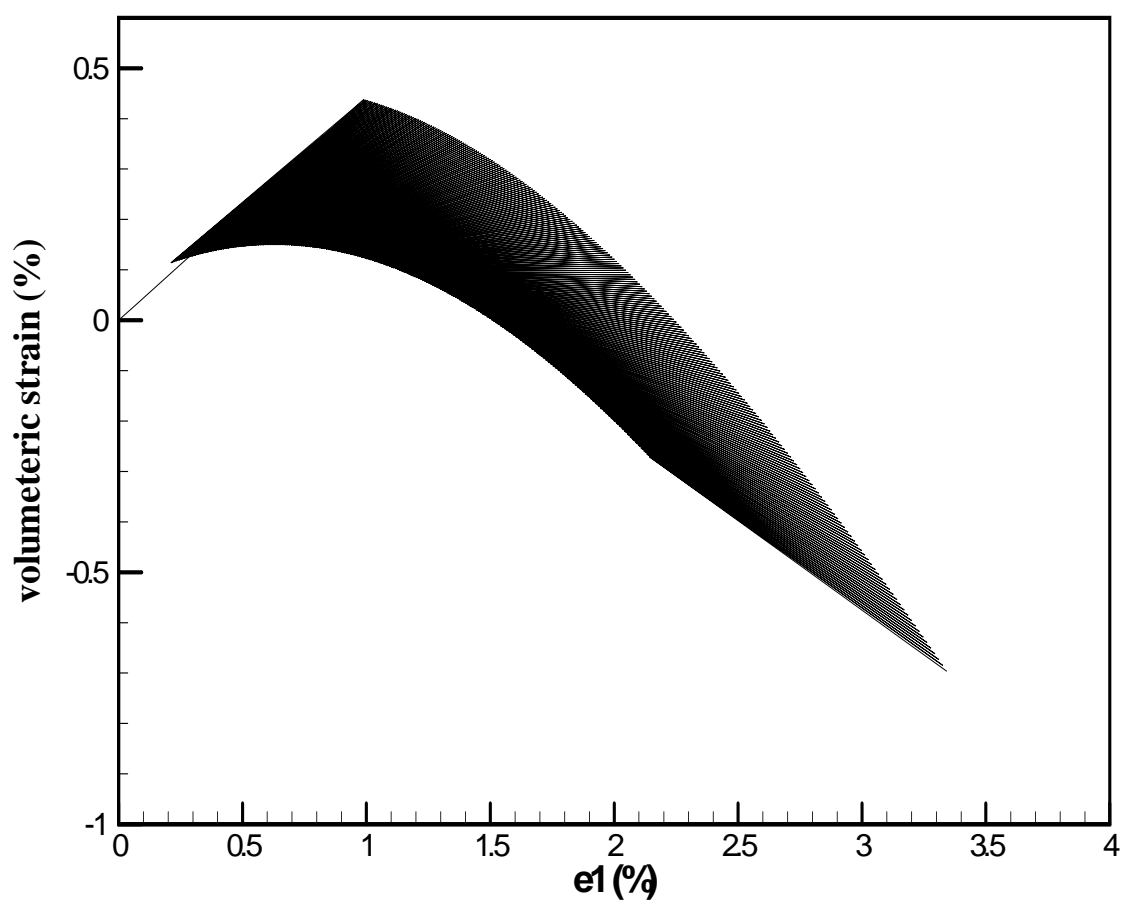

Figure (21): Cyclic volumetric strain-axial strain for confining 40MPa pressure (Multiline-Multilaminate Model)

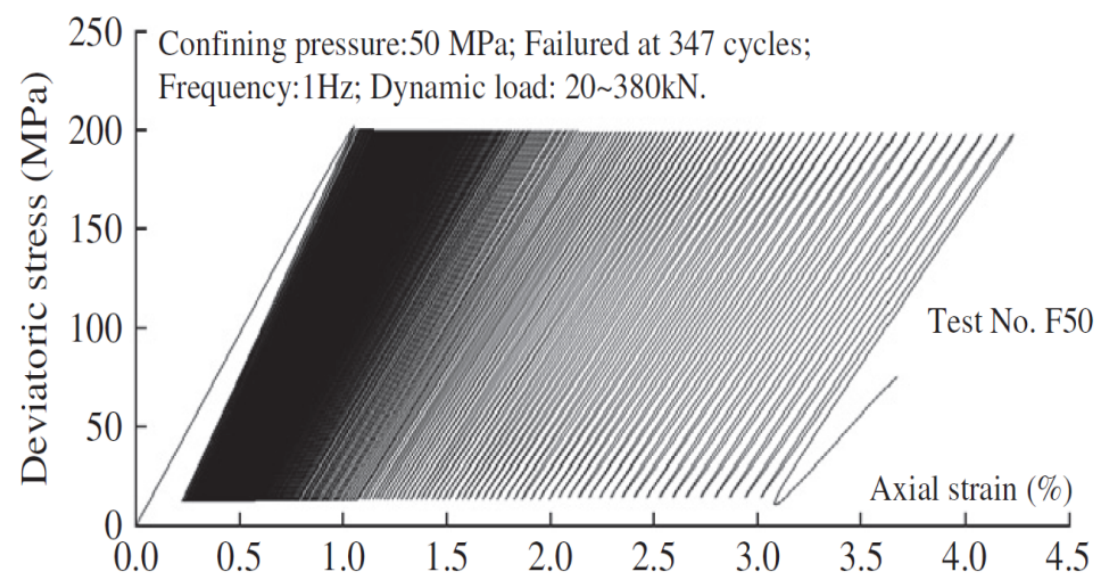

Figure (22): The laboratory results of the cyclic deviatoric stress-axial strain for confining 50MPa pressure [13]

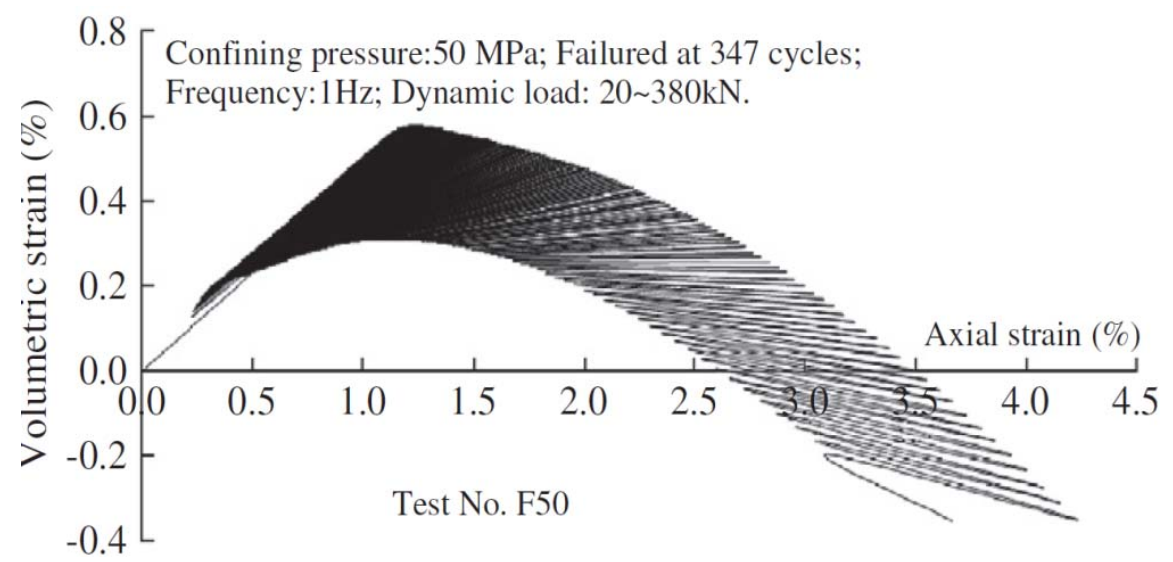

Figure (23): The laboratory results of the cyclic volumetric strain-axial strain for confining 50MPa pressure [13] 


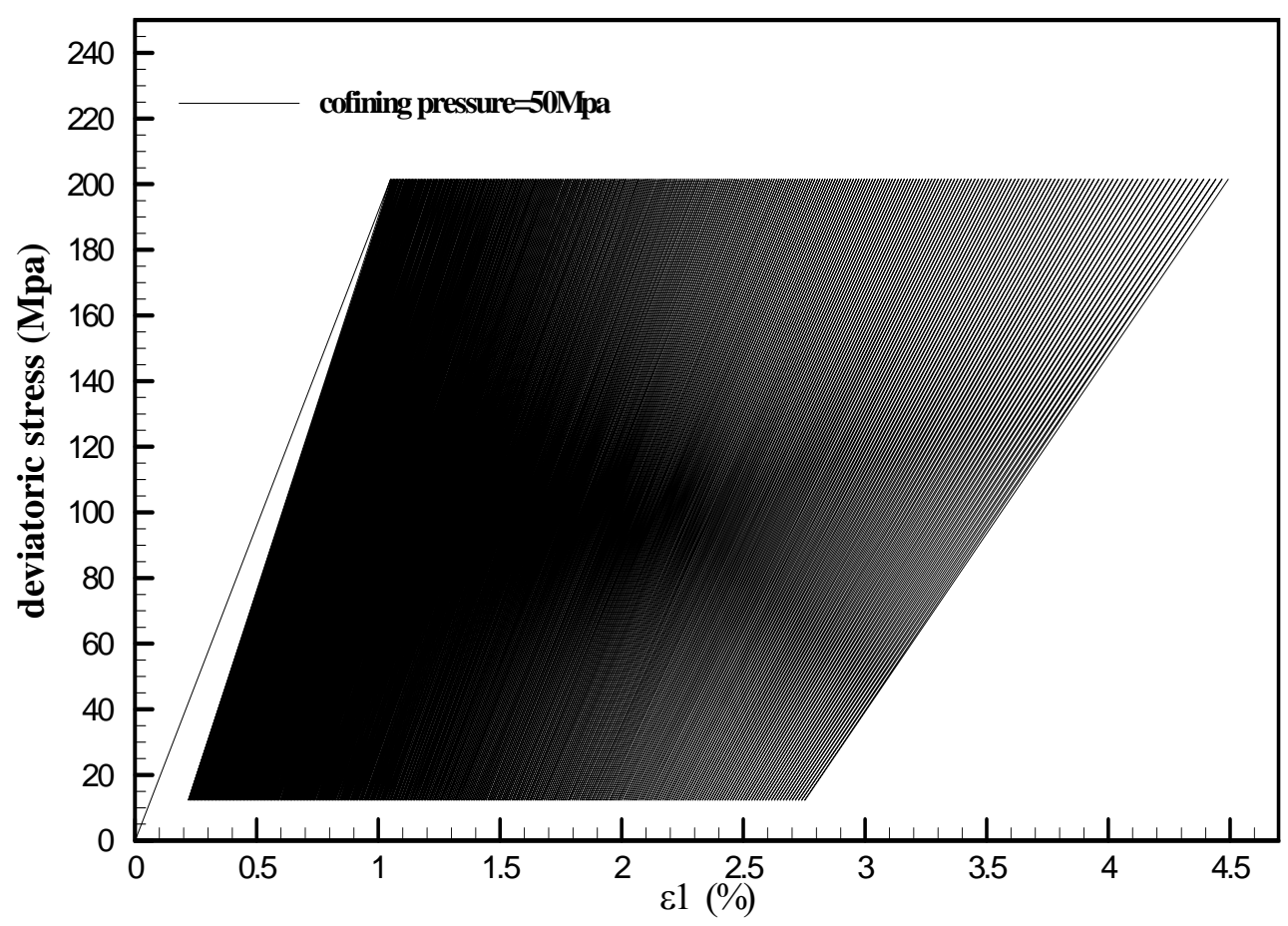

Figure (24): Cyclic deviatoric stress-axial strain for confining 50MPa pressure (Multiline-Multilaminate Model)

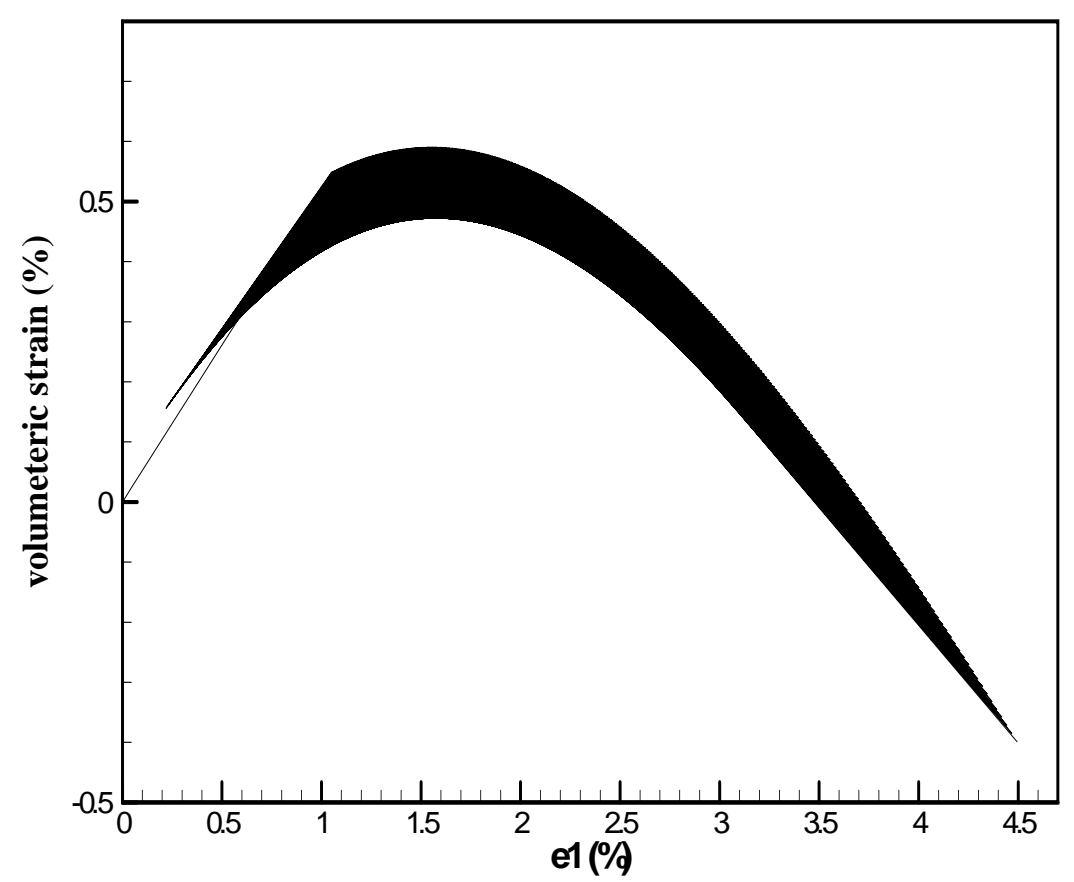

Figure (25): Cyclic volumetric strain-axial strain for confining 50MPa pressure (Multiline-Multilaminate Model) 


\section{Addition of the Behavioral Model to Numerical Software:}

The performance of the multilinear behavioral model was investigated within the format of multiplane theory. However, this behavioral model cannot be used in practice in numerical problems because the model works for one point and it has to be added to a type of numerical analysis software so that it can be practically used in engineering problems. The commercial software codes are very complex for finite element analysis for they include millions of code line. These software packages are closed-source but they have the capacity of accommodating simple elements and models. These software packages hardly become consistent with hardware changes and do not allow the researchers to change the important aspects of the codes. For example, in order to add a new behavioral model, a complete code should be written for software source. Hence, they are not suggested for the addition of new models [14].

One of the best aspects of the open-source software packages is that everybody can download the codes and make changes in them or add a new class of codes to them [14]. OpenSees is an open-source software package that is applied for finite element analysis. One of the goals of OpenSees is the use of modern software techniques for developing a finite element software database for earthquake engineering that can simultaneously incorporate structural and geotectonic engineering and adapt to the rapid changes of the hardware sources [14].

One of the other goals of OpenSees is providing a common analytical framework for the researchers to teach the university students and share novel knowledge with them [14]. Another goal of OpenSees is offering a mechanism for expansion of the new studies in the industry for examination and adaptation [14].

\section{Validation of the Numerical Software's Performance:}

After adding the new model to OpenSees, as a numerical analysis software package, it is necessary to reensure the accuracy of the multilinear behavioral model's performance within the format of multiplane theory. Thus, a laboratory standard triaxial cyclic experiment was conducted for a pressure rate of $10 \mathrm{KPa}$ in dynamic loading mode; the strain-stress and the volumetric strain-axial strain diagrams have been drawn for them with the same elements and the same boundary conditions and stresses as mentioned in [13]. The behavior of the model is assessed for the new model in finite element space and the results are compared with the laboratory findings.

After exerting the confining stresses, the time comes for the imposition of the deviatoric stress and the problem is analyzed for load control state and the stresses and the strains are extracted for element no.17 that is almost in the center of the specimen in cyclic (dynamic) loading mode; the deviatoric stress-axial strain and volumetric strain-axial strain curves are subsequently drawn and the findings are compared with the laboratory results.

\section{Conclusion:}

According to the obtained results, Multiline-Multilaminate Modelcan be used for the prediction of the liquefaction. After adding the behavioral pattern to the numerical analysis software, the results of the same standard triaxial experiment that had been predicted for the single-point state by the model, were predicted again by the software and a maximum $17 \%$ error was observed. The results were found completely matching with the single-point model in terms of the failure mechanism and planes' activities. The parameters required by the multilinear model were obtained again within the format of multiplane pattern simply and with no problem in a comparison of the results.

\section{References:}

[1] Nowzari, A., (2002), “offering a multilinear model of earth materials' behavioral analysis within the format of multiplane model”, Khajehh Nasir Al-Din Tusi.

[2] Guidelines of the seismic analysis and designing of earth-gravel dams, planning and budget vice chancellor of the presidency, 2013.

[3] Ports, D. and L. Zdravkovic, Finite element analysis in Geotechnical engineering. 2001, Thomas Telford, London.

[4] Stavrogin, A.N. and B.G. Tarasov, Experimental physics and rock mechanics. 2001: CRC Press.

[5] Bagde, M. and V. Petroš, Fatigue properties of intact sandstone samples subjected to dynamic uniaxial cyclical loading. International Journal of Rock Mechanics and Mining Sciences, 2005. 42(2): p. 237-250.

[6] Liu, E. and S. He, Effects of cyclic dynamic loading on the mechanical properties of intact rock samples under confining pressure conditions. Engineering Geology, 2012. 125: p. 81-91.

[7] O.C. Zeinkiewicz, G. N. Pande, "Time-Dependent Multi-Laminate Model for Rocks-A numerical study of Deformation and Failure of rock masses", Int. J. N. An. Meth. Geomech., 1997, (1), pp 219-247.

[8] S. A. Sadrnezhad,G. N. Pande, "A Multi-Laminate Model for Sand", Proceeding of 3rd International Symposium on Numerical Models in Geomechanics, NUMOG-III, 8-11 May, 1989, Niagara Falls, Canada.

[9] S. A. Sadrnezhad, Crack Analysis of Concrete Arch Dams Using Micro-Plane Damage Based Constitutive Relations, Science Publications, New York, USA, American Journal of Applied Sciences, April,2007,pp. 197-202.

[10] Ahmadi, N. and Sadrnejad, A., (2003), "multiplane elastoplastic model for predicting the behavior of sand in liequfaction phenomenon", international conference of civil engineering, $15^{\text {th }}$ to $17^{\text {th }}$ of May, Isfahan, p.61.

[11] S. A. Sadrnezhad, A Continuum/Discontinuum Micro Plane Damage Model for Concrete, International Journal of Civil Engineering, Oct. 2005, vol.5, No.3, paper138.

[12] Sadrnejad, A., (2011), "plastic limit of soil theory and modeling”.

[13] Liu, E. and S. He, Effects of cyclic dynamic loading on the mechanical properties of intact rock samples under confining pressure conditions. Engineering Geology, 2012. 125: p. 81-91.

[14] Adding a New Material or Element to OpenSees. 2016; Available from: http://opensees.berkeley.edu/wiki/index.php/Adding_your_own_Code. 